\title{
Editorial
}

Andrea Pötting

Physiotherapeutin und Redakteurin

andrea.poetting@thieme.de

\section{Miteinander statt gegeneinander}

_ Kita-Streik, Post-Streik, Bahn-Streik - und die Öffentlichkeit diskutiert mit. „Den Erziehern gönnen es alle, aber wir verdienen doch auch nicht mehr“, hörte ich vielfach von Physiotherapeuten, Architekten und Grafikdesignern in den heißen Streikwochen im Mai. Die Forderung, dass „wir doch verdammt noch mal auch streiken müssten", ist durchaus berechtigt. Doch für Physiotherapeuten ist ein Streik nicht die beste Lösung, da nur ein kleiner Teil der Beschäftigten in einer Gewerkschaft organisiert ist und die Vorzüge des Streikrechts genießen könnte. Mit Recht ist aber das Bedürfnis der Therapeuten groß, auf ihre Missstände aufmerksam zu machen: $z u$ wenig Lohn, zu hohe Ausbildungskosten, zu wenig Anerkennung, zu hohe Fortbildungskosten. Auch wir sind mehr wert!

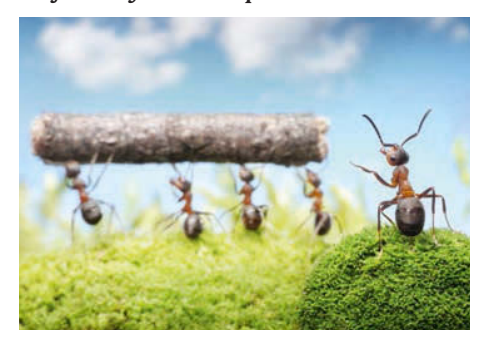

Über andere lustig machen ist einfach effektiver ist es, mitzuhelfen.

_ Die Hebammen haben es vorgemacht. Der Weg in das öffentliche Bewusstsein kann auch ohne Streik gelingen und baut Druck auf, der zu Veränderungen führt. Demonstrationen, Flashmobs, Medienbeiträge, Informationsveranstaltungen und Online-Petitionen - Wege gibt es viele, und: Keiner ist schlechter als der andere! Mit Entsetzen stelle ich fest, dass vor allem in der anonymen Netzwelt die Initiativen der einen von den anderen schlechtgemacht werden. Wir brauchen wohl keine Feinde, wir schaffen uns alleine! Warum nur? Lasst uns nicht Kraft verschwenden, indem wir uns selbst zerfleischen, sondern mit Kreativität und Engagement für unsere gemeinsamen Ziele kämpfen.

\section{Streikgeplagte Grüße}

Ihre

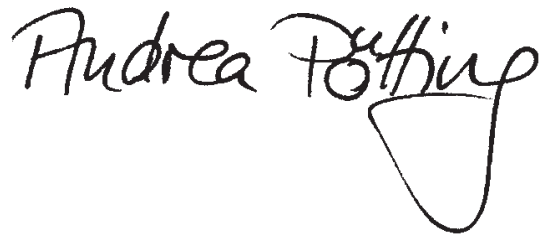

\section{ZU GEWINNEN}

In jeder physiopraxis werden attraktive Gewinne verlost. Möchten Sie einen ergattern, klicken Sie unter www.thieme.de/physiopraxis auf „Gewinnspiel“.

Und das gibt es in dieser Ausgabe zu gewinnen:

Bücher

3-mal „Den Schmerz in den

Griff bekommen"

Seite 36

2-mal „Rücken Qi Gong“ Seite 55

und außerdem ...

2 Gyrotwister

2 Kettlebells

1 Schröpf-Set

1 Vase DECADE

1 Samowar

1 Schale Kala L 